\title{
Watershed modeling using arc hydro based on DEMs: a case study in Jackpine watershed
}

\author{
Zhong Li
}

\begin{abstract}
Background: Raster-based digital elevation models (DEMs) play an important role in distributed hydrologic modeling supported by geographic information systems (GIS). In this study, DEMs and stream network data were used to model the Jackpine Watershed in Ontario, Canada, using Arc Hydro Tools.

Results: The modeling results include stream network and catchment delineation. The effects of the DEM reconditioning process and the stream threshold value on the modeling accuracy were examined through three simulations. The accuracy was discussed by overlying the actual and simulated maps, as well as by comparing stream densities, network lengths and numbers of streams, catchment area, and number of catchments. Other possible methods to improve the watershed modeling were also discussed.

Conclusions: It is concluded that Arc Hydro is capable of performing watershed modeling with satisfactory performance. It is shown that DEM reconditioning can improve the accuracy of watershed modeling. It is also implied that lower stream threshold value can not only lead to a more detailed stream network but also enhance the accuracy of catchment delineation.
\end{abstract}

Keywords: Digital elevation models; Watershed modeling; Stream network; Catchment delineation; Arc Hydro; ArcGIS

\section{Background}

Hydrologic models and the associated flooding models, water pollutants transportation models and water supply models are usually integrated in Geographic Information System (GIS) for distributed hydrologic stimulations (Fairfield and Leymarie 1991; Konadu and Fosu 2009; Moharana and Kar 2002; Wu et al. 2008). Extracting characteristics of the watershed, such as stream network and catchment delineation is essential for hydrological analysis and water resource management in GIS (Zhang et al. 2013). The foundation of these hydrologic models lies on how to obtain hydrologic and topographic parameters, i.e. watershed characteristics, from Digital Elevation Models (DEMs) (Ames et al. 2009; Jenson 1991; Lacroix et al. 2002).

There were many studies on the algorithms of watershed characteristics extraction in the past 20 years

Correspondence: keely.lee@gmail.com

Institute for Energy, Environment and Sustainable Communities, University of Regina, Regina, Saskatchewan S4S 0A2, Canada
(Jones 2002; Turcotte et al. 2001; Fairfield and Leymarie 1991; Zhang et al. 2013). Wu et al. (2008) discussed about DEM-derived primary topographic attributes for hydrologic applications. Zhang and Huang (2009) and Zhang et al. (2013) proposed an algorithm to establish channel networks in digital elevation models. Many GISbased tools have been developed based on the previous researches. The "Hydrology" toolset in ArcGIS, developed by Esri (2004), has been commonly used for DEM preprocessing and surface stream simulation. WinBasin is a watershed analysis system that can automatically calculate depressionless flow directions, delineate watersheds/subwatersheds, extract realistic drainage networks, and calculate geomorphologic indices and hydrological responses from DEMs (Lin et al. 2008). NRCS GeoHydro is an ArcGIS application that can compute catchments, drainage points, drainage lines, and cross-section details for a storm event hydrologic model (Merkel et al. 2008). Arc Hydro is an ArcGIS-based system geared to support application involving water resources. There are two key components, 


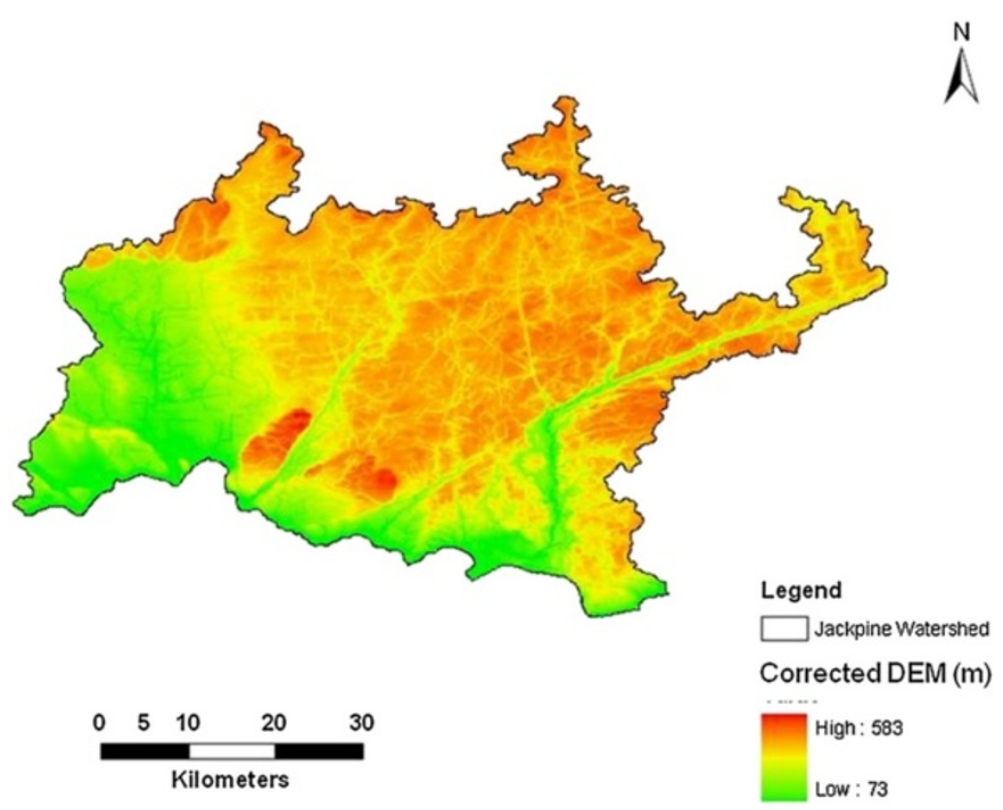

Figure 1 The corrected DEM of Jackpine watershed.

including Arc Hydro Data Model and Arc Hydro Tools. These two components, together with the generic programming framework, provide basic database design and set of tools that facilitate analysis often performed in the water resources area (ESRI 2004). With these tools, watershed characteristics such as stream network, flow length, catchment, and channel networks can be rapidly and reliably determined or extracted from DEMs (Lin et al. 2008). However, few has been done to analyze the effects of DEM processing on watershed modeling accuracy (Konadu and Fosu 2009; Murphy et al. 2007). Therefore, the objective of this study is to extract the characteristics of the Jackpine watershed in Canada, and to investigate influential factors on the modeling accuracy. The stream network and catchment in the study area will be modeled based on DEMs using Arc Hydro tools. Three simulations will be conducted to analyze the factors that influence the modeling accuracy.

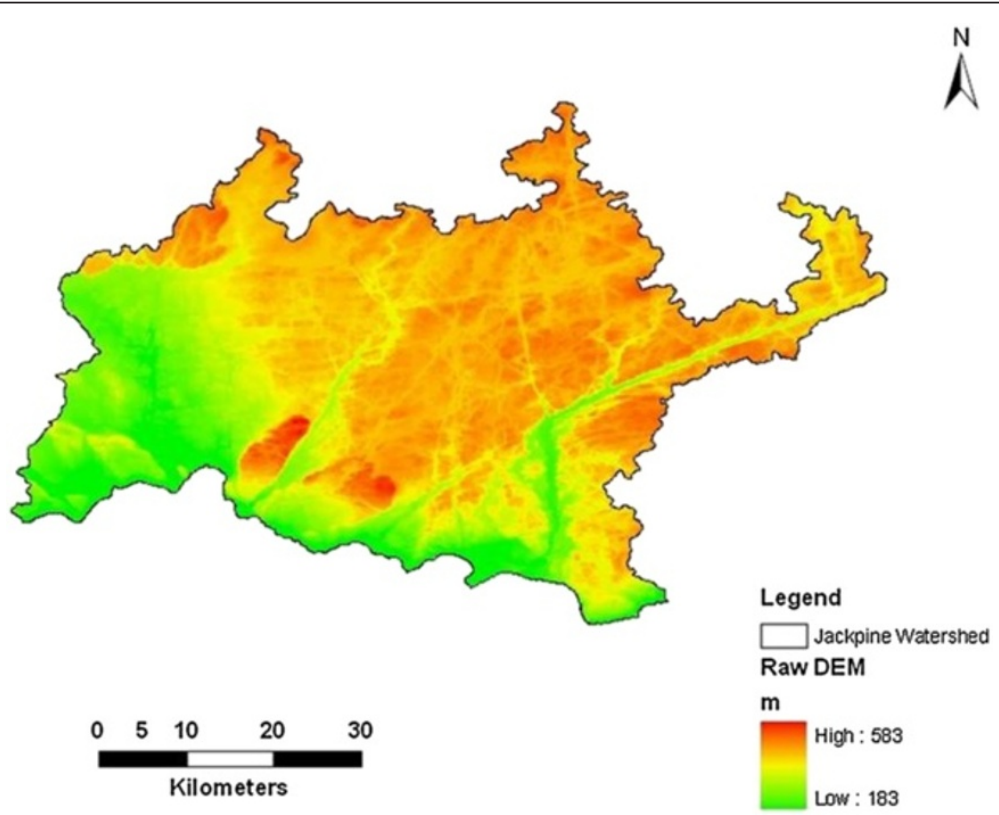

Figure 2 Original digital elevation map of the Jackpine watershed. 


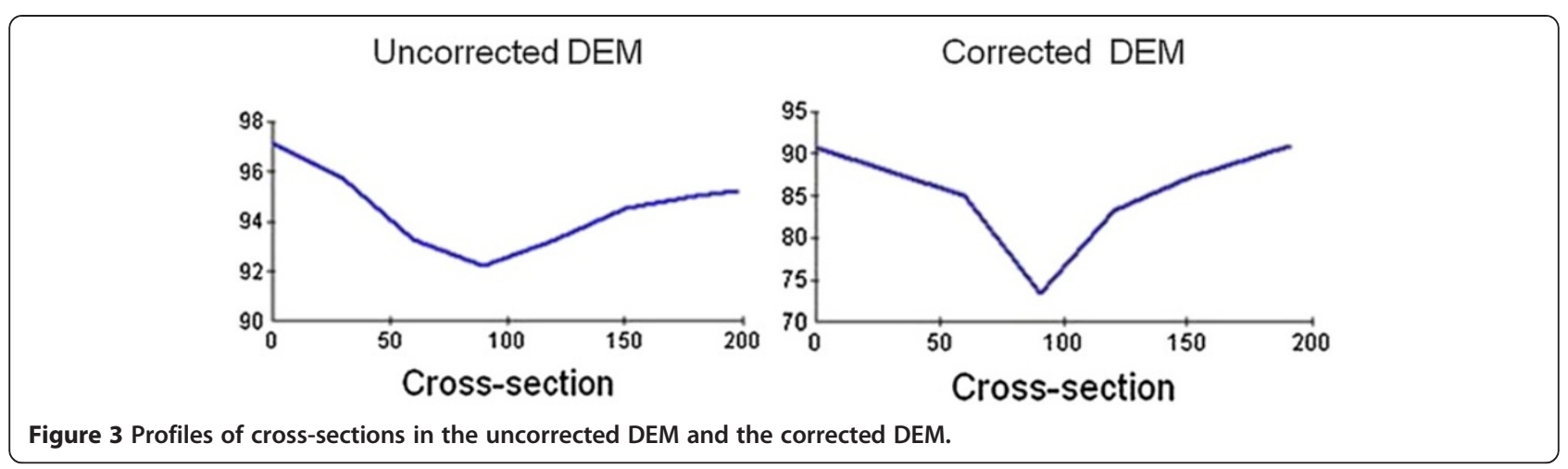

\section{Results and discussion DEM reconditioning}

DEM Reconditioning is an implementation of the "AGREE" method of hydrological correction. In this process, original DEMs were input and stream network were also input as a linear feature class. After the reconditioning, the elevation in the DEM dropped or raised a certain amount depending on the linear feature class. Integer values for sharp drop raise, smooth drop raise and stream buffer in this process were 10,10 , and 5 , respectively. Figures 1 and 2 present the corrected and the original DEMs. The lowest elevation in the uncorrected DEM was $183 \mathrm{~m}$; whereas the lowest elevation was $73 \mathrm{~m}$ in corrected DEM. Profiles across streams were examined using ArcGIS 3D analyst to show the elevation correction (Figure 3). In the corrected DEM, the elevation of the cells that overlaid with the stream network dropped. The DEM reconditioning process was conducted in Simulations B and C.

\section{Stream network simulation}

Even though the DEM data and parameter settings were different in the three simulations, the procedures of the simulation were similar. Results of the main steps in Simulation A are presented in Figures 4, 5 and 6 to show the simulation process. Artificial depressions in the input DEMs were filled using the "Fill Sink" function, then the flow direction map was created using "Flow Direction" function. In the flow direction map, the values of $1,2,4,8,16,32,64$, and 128 represented eight possible

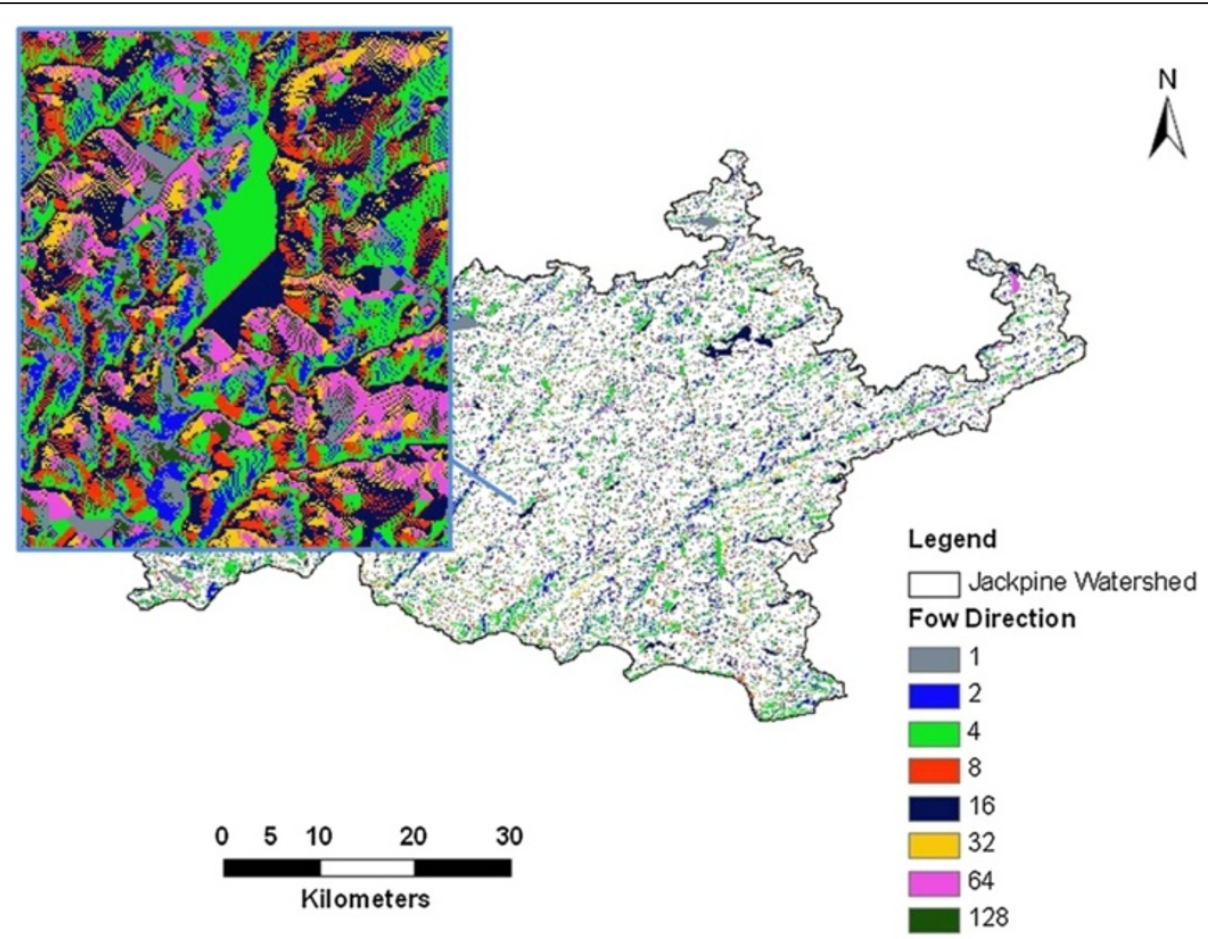

Figure 4 Flow direction map of simulation A. 


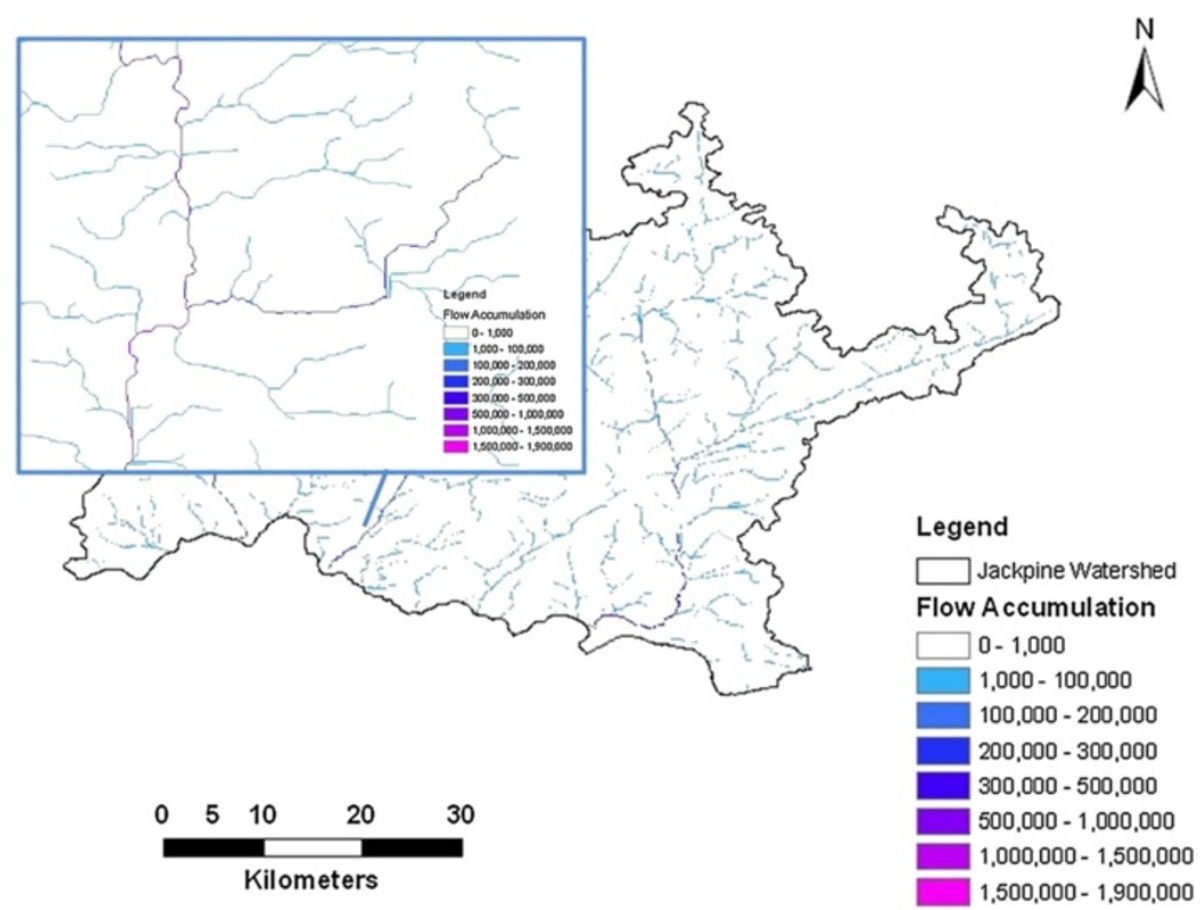

Figure 5 Flow accumulation map of simulation A.

direction of the flow in each cell (Figure 4). Flow accumulation network (Figure 5) was then created based on the flow direction using the "Flow Accumulation" function. With the "Stream Definition" function, all the cells in the input flow accumulation grid that had a value greater than the given threshold grid was given a value of "1" and defined as stream grid. After linking the stream grid using the "Stream Segmentation" function, the Stream Link grid map was produced (Figure 6). Based on this map, drainage lines, i.e., stream network, were created using the "Drainage Line Processing" function, and catchments were created using the "Catchment Grid Delineation" and "Catchment Polygon Processing" function.

\section{Results of the three simulations}

Comparisons of the simulated stream networks and the actual stream network are presented in Figures 7, 8 and 9.

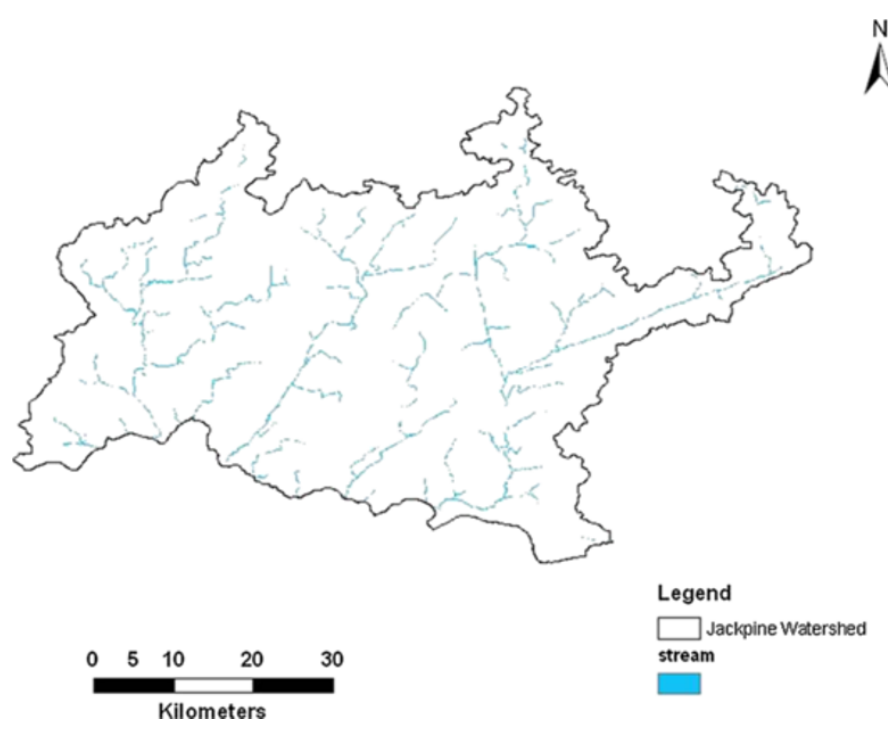

Figure 6 Stream link grid map of simulation A. 


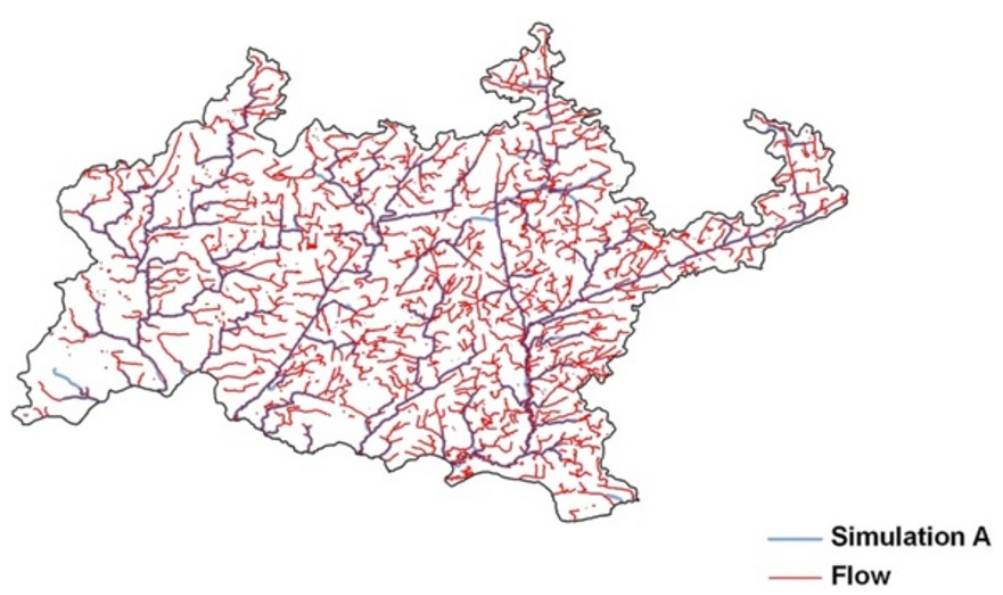

Figure 7 The comparisons of the actual stream network and stream network in simulation A.

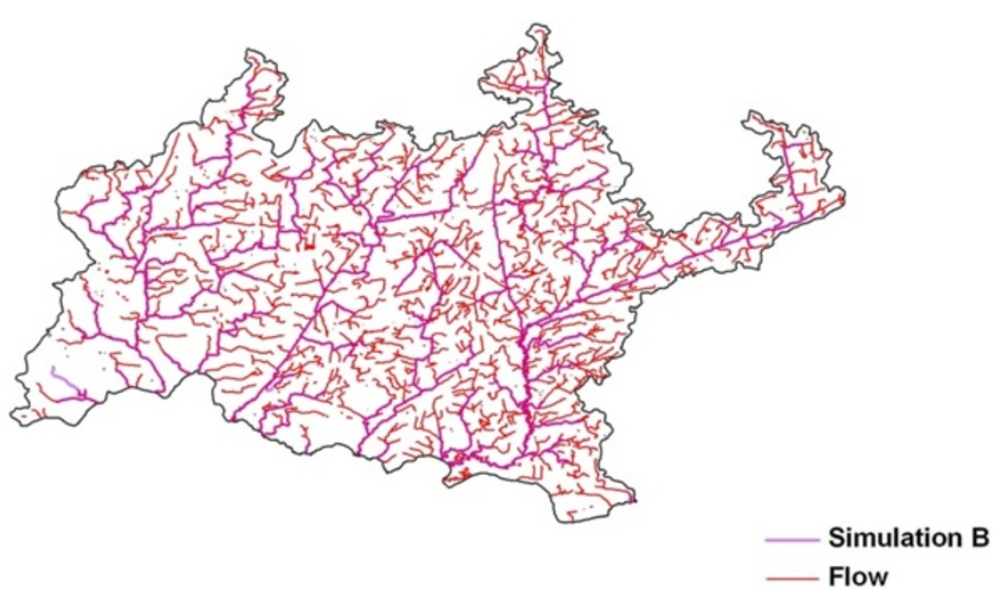

Figure 8 The comparisons of the actual stream network and stream network in simulation B.

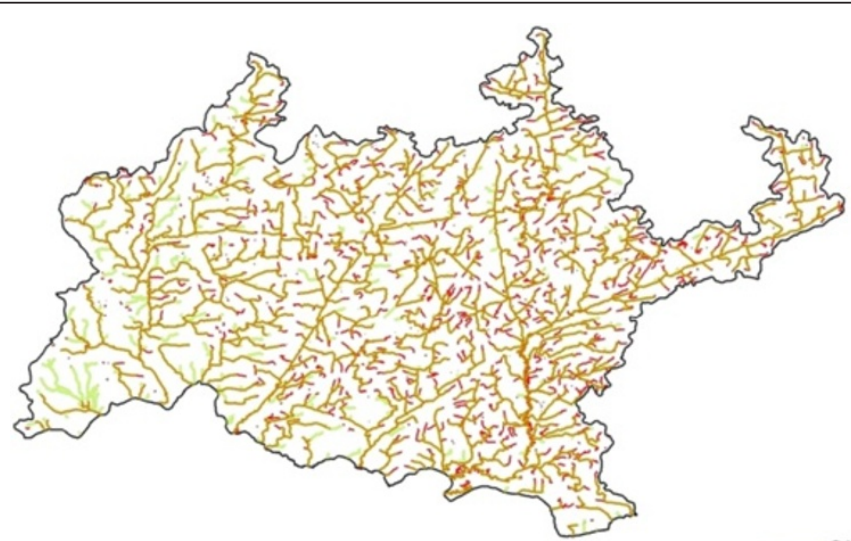

Simulation C

Flow

Figure 9 The comparisons of the actual stream network and stream network in simulation C. 


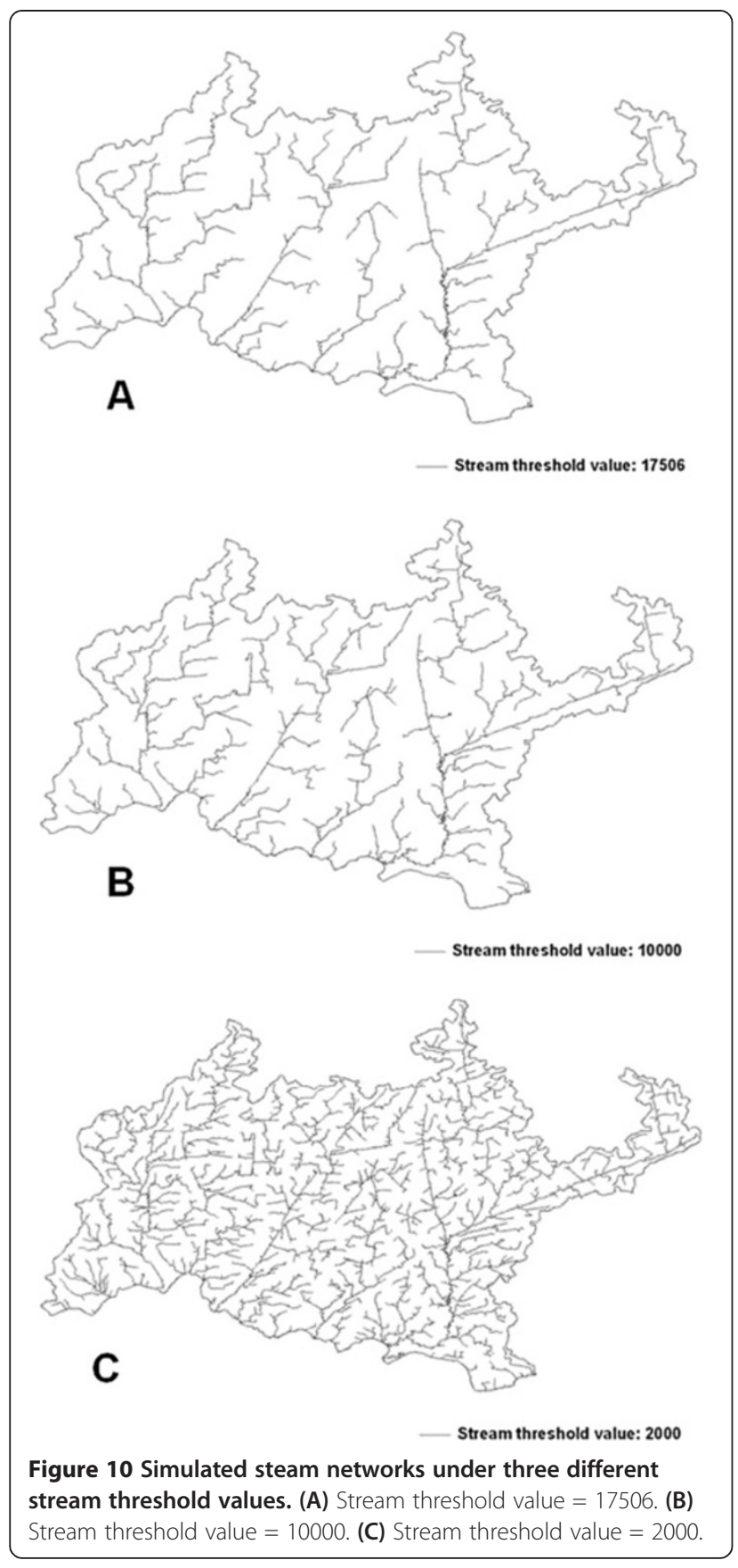

In Simulation A and B, default stream threshold values (i.e., 18919 and 17506, respectively), which were $1 \%$ of the maximum flow accumulations, were used. The stream threshold values were relatively high (comparing to the suggested value $500-1000$ ), thus only the main streams were extracted in these two simulations. Deviations of the simulation results were marked out in the comparison figures. Comparing to the results of Simulation B, the differences between the actual and simulated stream networks were much more noticeable. This might result from the fact that the DEMs in Simulation B had been preprocessed with hydrological correction while those in Simulation A had not. Hydrological correction could enhance the accuracy of stream network simulation and thus the watershed delineation (Zhang et al. 2013).

Stream threshold value is an important factor that influences the simulation. Simulation results under different stream threshold values are shown in Figure 10. It is shown that the higher the stream threshold values is, the lower the density of simulated stream networks would be. In Simulation C, the steps of stream network simulation were repeated for times to find the stream threshold value that brought the best match to the original stream network. The stream threshold value 2000 resulted in a map with a similar stream density as that of the actual stream network, thus 2000 was chosen as the optimal stream threshold value. In Simulation C, both the stream density and the mainstreams shows desirable match with the actual watershed. However, deviations of the simulated results were found in Simulations B and C where hydrological corrections were conducted (Figures 8 and 9). This proved that even though the original DEMs were corrected by "burning" the actual stream network, deviations still happened. There is a high possibility that the deviations were resulted from local precipitation, DEM resolutions or the algorithms of flow direction and flow accumulation functions in Arc Hydro, and it could not be avoid by changing parameter settings.

Comparison of the simulated catchments and the actual watershed boundary are presented in Figure 11. The difference between the simulated catchments and the actual watershed was relatively large in Simulation $\mathrm{A}$ and B, whereas the simulated catchment in Simulation $\mathrm{C}$ matched the actual watershed much better. The results in Simulation $\mathrm{C}$ demonstrated that, with the lower the stream threshold values, more detailed and accurate catchment delineation could be obtained.

Table 1 summarizes the comparison of stream networks and catchments. Statistics of the stream networks and catchments in the three simulations are presented in Figures 12 and 13. The network length, number of streams, catchment area, and number of catchment in Simulation A and B were similar, and they were all much less than those in the actual watershed. However, the results in Simulation $C$ were much higher, and were close to the values in the actual watershed. The reason might be that a lower stream threshold value led to a much more detailed stream network with more second-order and third-order streams in Simulation C. The detailed stream network resulted in a long network length, a large number of streams, and a large number of catchments. The larger the number of catchments is, the more detailed the catchment delineation would be. Therefore, the lower stream threshold value eventually resulted in more detailed and more accurate catchment area. 

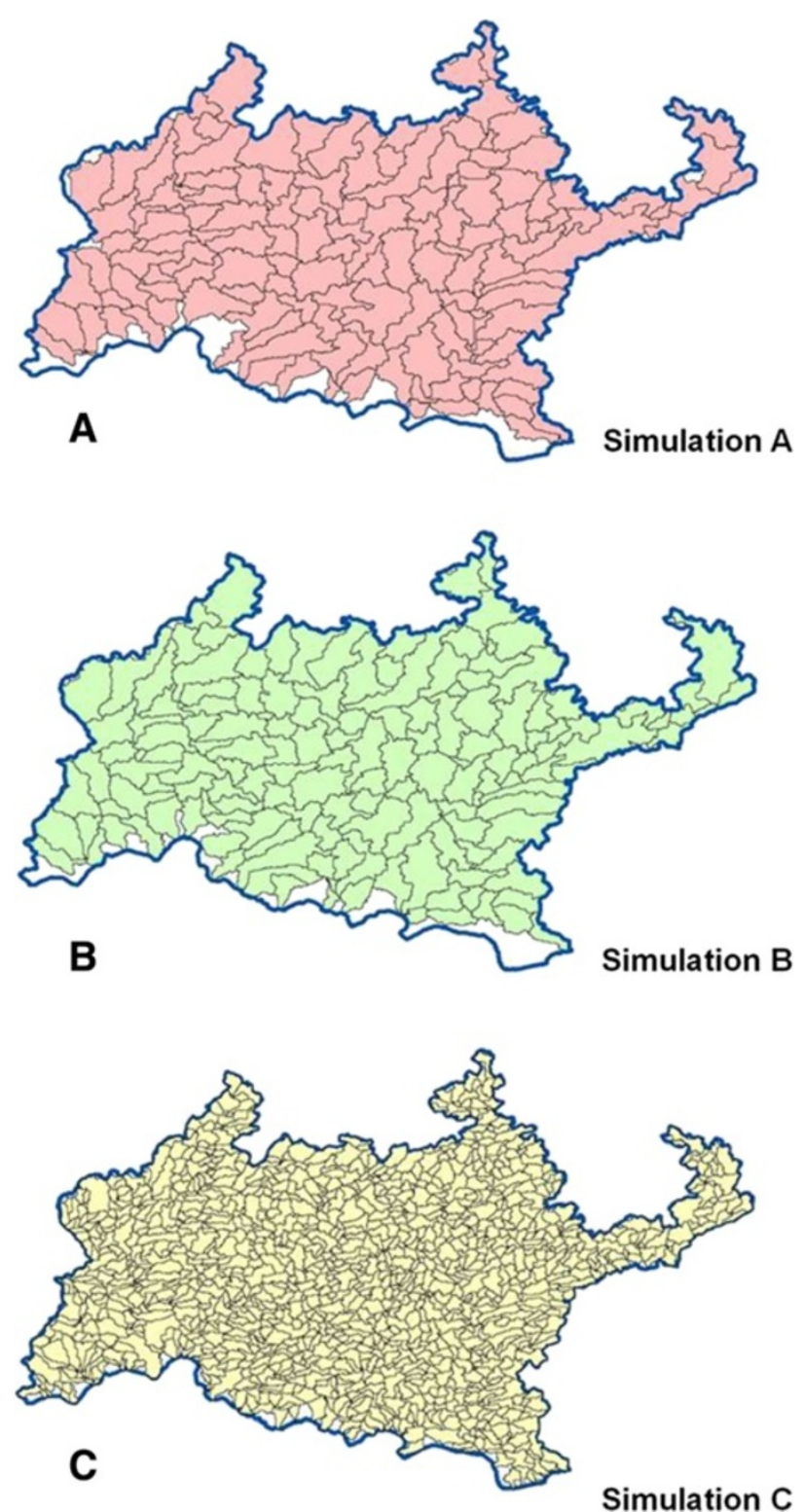

\section{Legend}

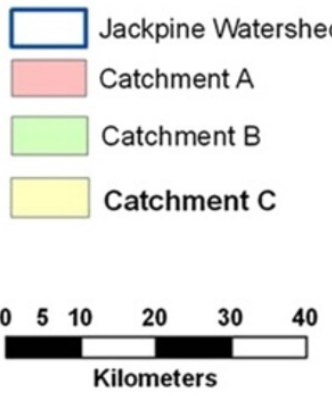

Figure 11 Comparison of the catchment delineation in three simulations. (A) Catchment delineation results in simulation A. (B) Catchment delineation results in simulation B. (C) Catchment delineation results in simulation C).

\section{Conclusion}

The stream network and catchment of Jackpine watershed in Ontario were modeled in three simulations using Arc Hydro. The three simulations were designed to analyze how the DEM reconditioning process and stream threshold value would effect on the accuracy of stream network and catchment modeling. The accuracy were examined by overlaying the actual and simulated map as well as by comparing the stream densities, network lengths, numbers of streams, catchment areas and

Table 1 Summary of stream networks and catchments compared

\begin{tabular}{lcccc}
\hline & Network length $(\mathbf{k m})$ & Number of streams & Catchment area $\left.\mathbf{( k m}^{\mathbf{2}}\right)$ & Number of catchments \\
\hline Original stream & 2082.4 & 5054 & 1868.2 & - \\
Simulation A & 565.1 & 148 & 1728.4 & 148 \\
Simulation B & 648.1 & 155 & 1744.2 & 155 \\
Simulation C & 1758.2 & 1374 & 1803.4 & 1374 \\
\hline
\end{tabular}




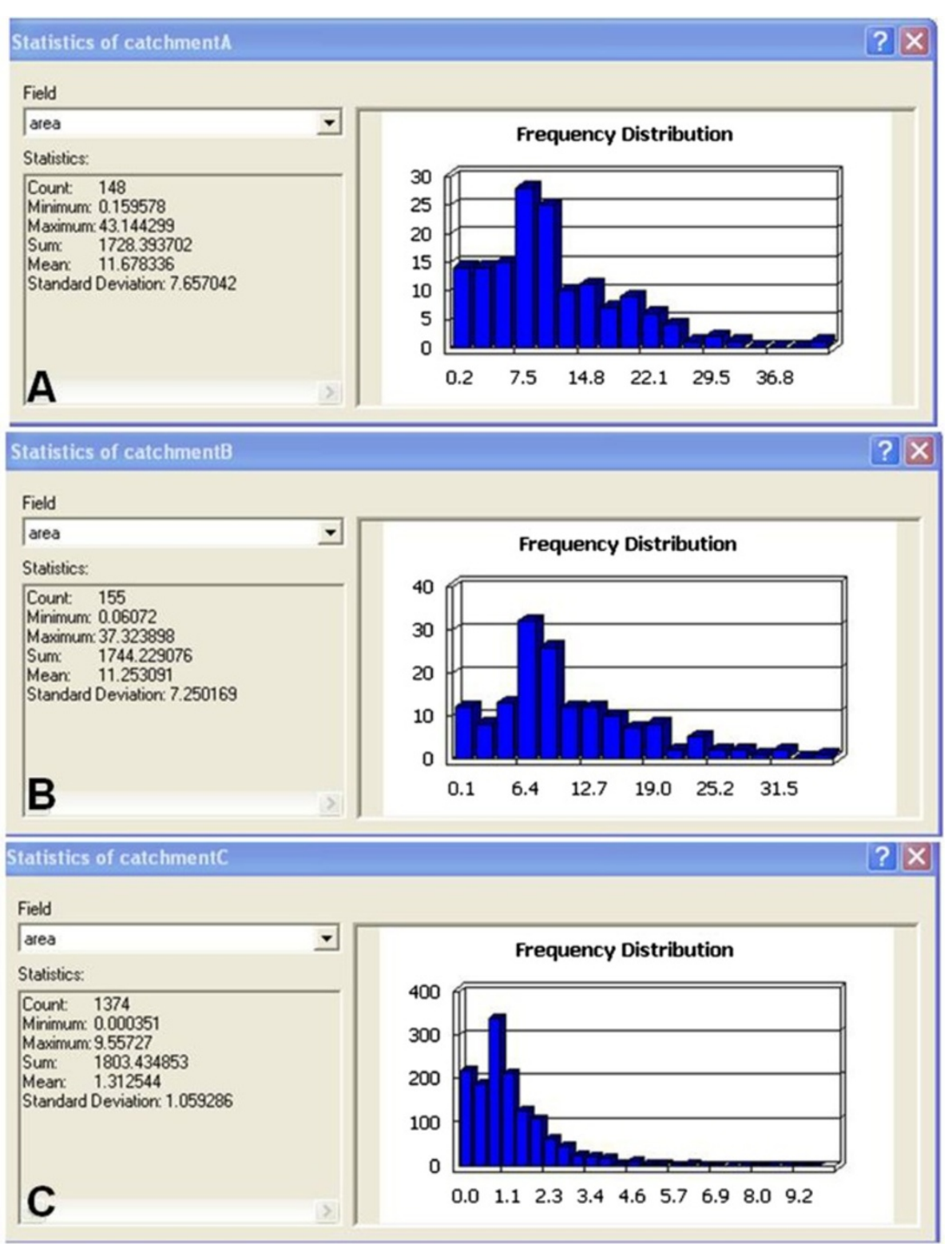

Figure 12 Statistics of the catchments in three simulations. (A). Statistics of catchments in simulation A. (B). Statistics of catchments in simulation B. (C). Statistics of catchments in simulation C.

numbers of catchments. The results demonstrated that Ayc Hydro could provide watershed simulation with satisfactory performance. It was proved that DEM reconditioning could improve the accuracy of watershed modeling, and that lower stream threshold value could not only lead to a more detailed stream network but also improve the accuracy of catchment modeling. However, even though DEM recondition was processed and the optimal stream threshold value was chosen, there were still deviations in the simulated results. It is believed that other factors, such as local precipitation, DEM resolution, parameter values and flow calculation algorithms might be the reason of deviations.
Extracting characteristics of a watershed from DEM dataset is essential for hydrological analysis. It is the first step of process analysis in distributed hydrological models. The results could be further applied to many other watershed characteristics extraction and watershed delineation applications, and provide decision support for water resources management in various regions.

There are many factors that might influence the accuracy of watershed modeling with Arc Hydro, but only the DEM reconditioning and stream threshold value were examined in this study. Therefore, future work with the consideration of more factors, such as 


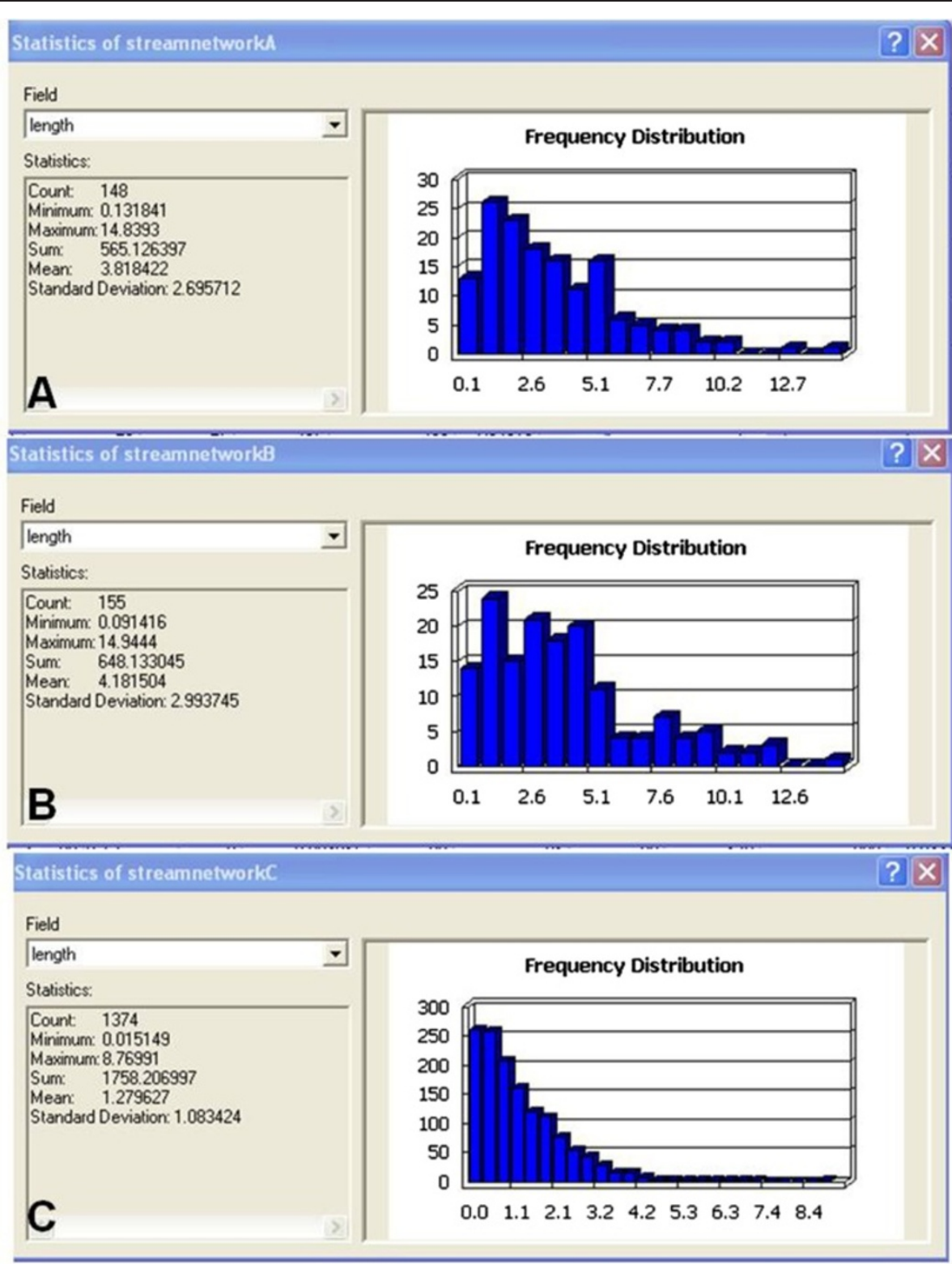

Figure 13 Statistics of the streams in original flow map and three simulations. (A). Statistics of catchments in simulation A. (B). Statistics of catchments in simulation B. (C). Statistics of catchments in simulation C.

DEM resolution and other parameter setting in Arc Hydro is desired. More research on the flow calculation algorithms would also help improve the accuracy of watershed modeling.

\section{Methods}

\section{Study area}

The Jackpine watershed, a watershed in the Great lakes St. Lawrence Drainage Area in Ontario, Canada, was chosen as the study area (Figure 14). The total area of the watershed is $1868.2 \mathrm{~km}^{2}$. It is a tertiary watershed of the secondary watershed Northwestern Lake Superior in Great lakes - St. Lawrence Basin.

The study area is affected by both warm, humid air from the Gulf of Mexico and cold, dry air from the Arctic. The Great Lakes have a significant influence on the climate in this watershed. Acting as a giant heat sink, the lakes moderate the temperatures of the surrounding land, cooling the summers and warming the winters (Magnuson et al. 1997). Climate is milder in this watershed compared to other locations of similar latitude. The lakes also increase the moisture content of the air in the watershed throughout the year. 


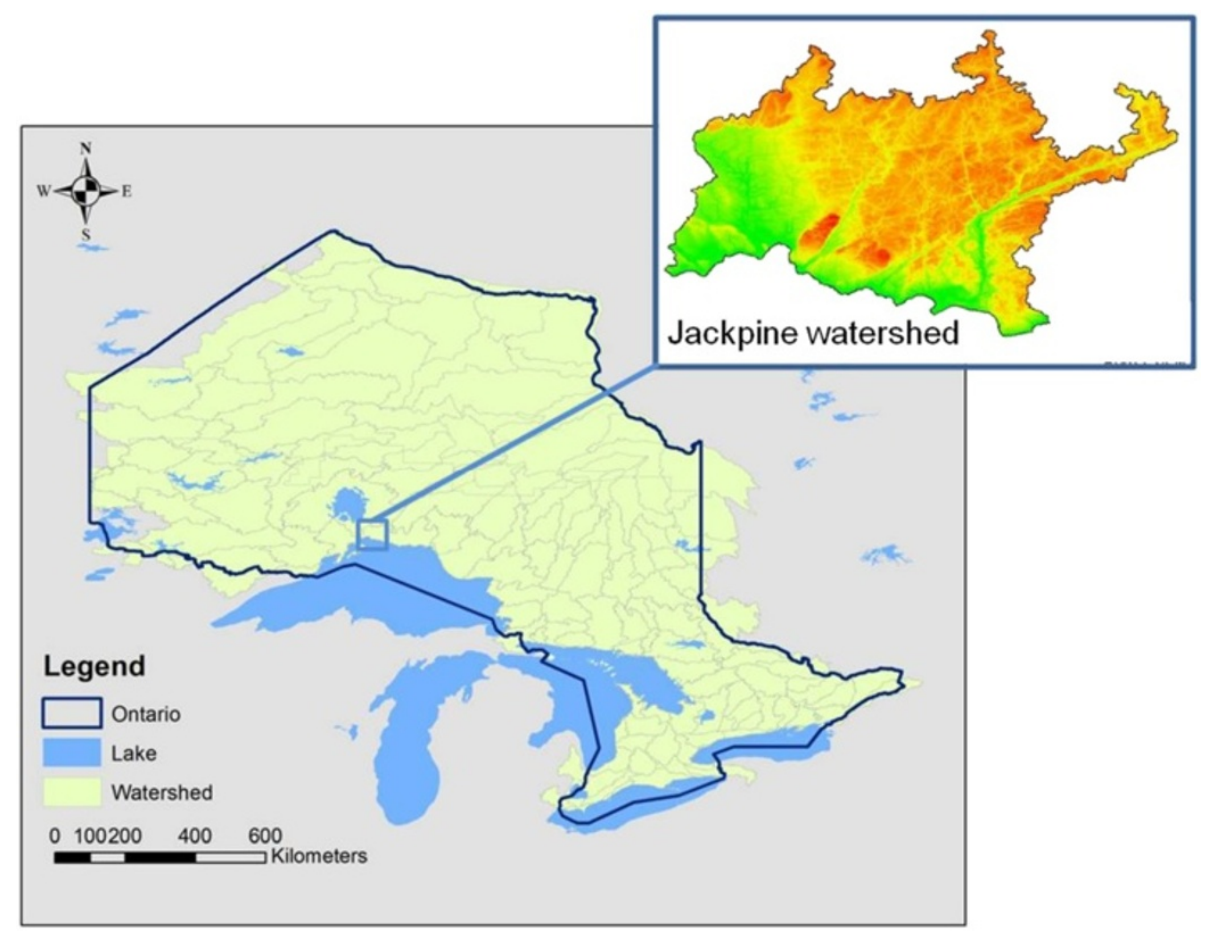

Figure 14 Location of the study area and watershed in Ontario, Canada.

\section{Watershed boundary and stream network data}

Watershed boundary and stream network data were extracted from the National Hydro Network (NHN) data on the GeoBase Web portal of Canada. NHN is a geospatial database that covers the inland surfaces water in Canada. It is in vector format following the international geometrics standards. The boundary of Jackpine watershed was defined by NHN Work Unit Limit, which generally corresponds to the Water Survey of Canada Sub-Sub-Drainage Areas. The NHN

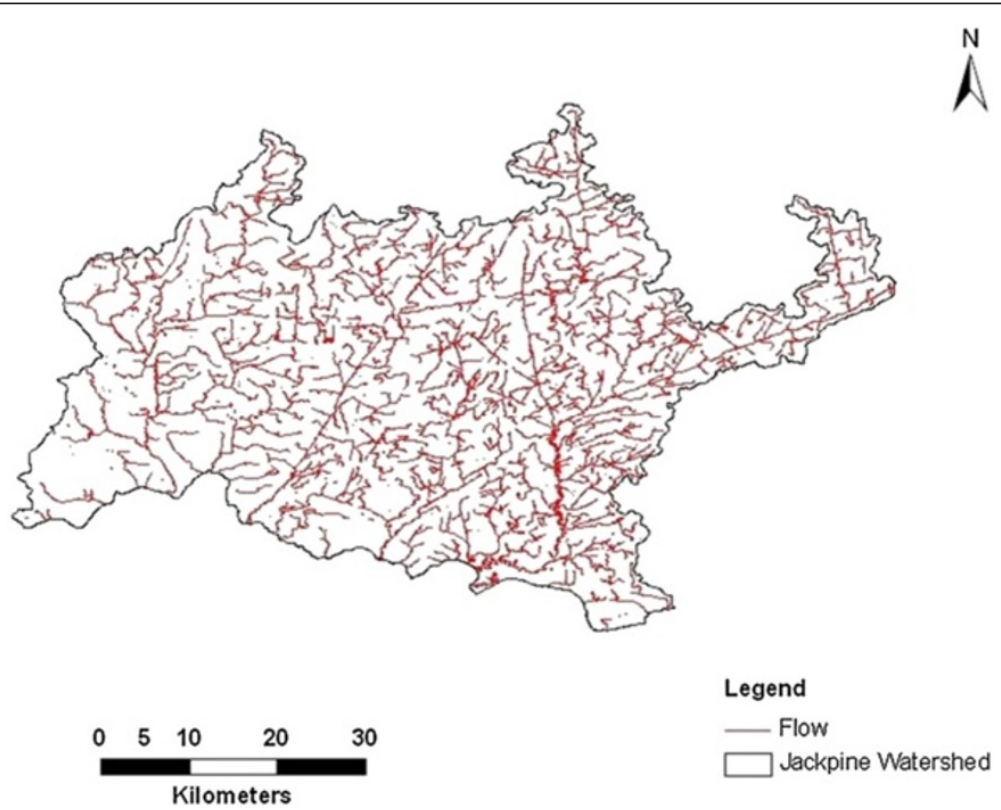

Figure 15 Watershed boundary and stream network of Jackpine watershed derived from National Hydro Network (NHN) data. 
Table 2 Main parameter settings of simulation A, B, and $C$

\begin{tabular}{ccc}
\hline Simulation & DEM processing & Stream threshold value \\
\hline A & Without hydrological correction & Default value: 18919 \\
B & With hydrological correction & Default value: 17506 \\
C & With hydrological correction & 2000 \\
\hline
\end{tabular}

data of Jackpine watershed was downloaded as a NHN dataset. Watershed boundary and stream network data are presented in Figure 15.

\section{Digital elevation model sources}

Digital elevation data was collected from the GeoBase Web portal of Canada. The source data was extracted from the National Topographic Data Base (NTDB) or various data acquired from the provinces and territories. Digital data at the scale of 1:50,000 were chosen for the study area. The grid spacing, based on geographic coordinates, was in the resolution of 0.75 arc seconds. Ground Elevations were recorded in meters relative to Mean Sea Level (MSL), based on the North American Datum 1983 (NAD83) horizontal reference datum. The DEM sections were first converted to raster files and then combined using ArcGIS tools. The obtained DEM map of Jackpine watershed is shown in Figure 2.

Modeling stream networks using digital elevation models The modeling of stream network was based on the aforementioned stream network and DEMs data using the functions in the Arc Hydro application. A depressionless DEM was created based on the input DEM to ensure that flow was not altered by artificial depressions. The flow direction algorithm D8 (i.e., deterministic eight-node algorithm) was used to produce a grid of flow directions. This grid was used to produce the surface flow accumulation network. All the cells in the flow accumulation grid that had a value greater than the given threshold grid was given a value of " 1 " and defined as stream grid. Stream segments that might be a head segment, or might be defined as a segment between two segment junctions were created to produce a stream link grid map. Finally, the drainage line and catchment delineation were obtained based on the stream link grid.

In Arc Hydro, the original DEM grid can be further enhanced by overlaying and "burning" hydrographic details such as streams, lakes, and shorelines into this grid, to ensure that the modeled flow is forced to conform to already mapped surface water features (Saunders 2000; MacMillan et al. 2003). This is also called the "DEM reconditioning", which uses the "AGREE" method and produces a "hydrologically corrected” DEM (Zhang et al. 2013). Although there is still little published work about this process in peer-reviewed journals, there are numerous studies in reports and on the internet and it has been adopted for the USGS National Hydrography Dataset (Murphy et al. 2007).

The conventional watershed simulation process includes sink filling, flow direction determination, flow accumulation and stream definition (Zhang and Huang 2009). Parameters in DEM preprocessing as well as in all of the watershed simulation steps might have effects on the accuracy of the modeled stream network. In order to compare the effectiveness of the hydrological correction using "DEM reconditioning", Simulation A and Simulation B were designed. In Simulation $C$, steps of the simulation were repeated for times using different threshold and integer values to match the original stream network. Main parameter settings of the three simulations are shown in Table 2. The flowchart of this work is shown in Figure 16.

\section{Competing interests}

The author declares that she has no competing interests.

\section{Authors' contributions}

ZL carried out the watershed modeling and result analysis, wrote and approved the final manuscript.

\section{Acknowledgements}

The work was supported by China Scholarship Council and Faculty of Graduate Studies \& Research, University of Regina. The author would like to express thanks to Dr. Joe Piwowar his constructive comments and suggestions.

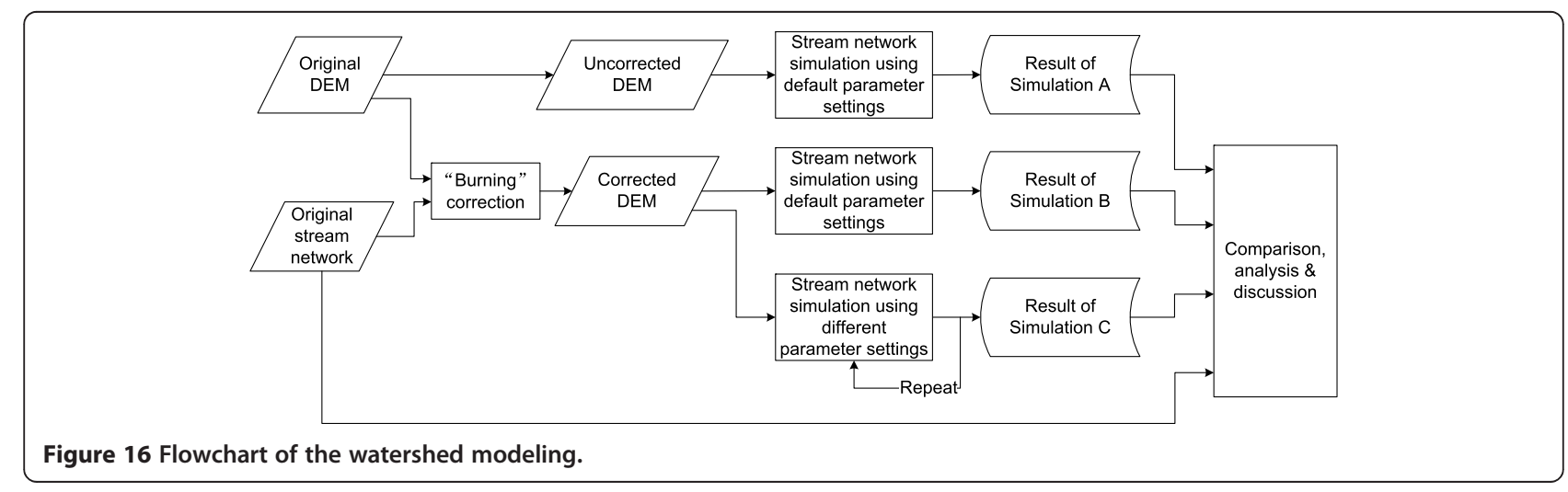


Received: 11 December 2013 Accepted: 8 January 2014

Published: 11 March 2014

\section{Reference}

Ames D, Rafn E, Van Kirk R, Crosby B (2009) Estimation of stream channel geometry in Idaho using GIS-derived watershed characteristics. Environ Model Softw 24(3):444-448

ESRI (2004) Arc hydro tools overview. ESRI, United States of America

Fairfield J, Leymarie P (1991) Drainage networks from grid digital elevation models. Water Resour Res 27(5):709-717

Jenson S (1991) Applications of hydrologic information automatically extracted from digital elevation models. Hydrol Process 5(1):31-44

Jones R (2002) Algorithms for using a DEM for mapping catchment areas of stream sediment samples* 1 . Comput \& Geosciences 28(9):1051-1060

Konadu D, Fosu C (2009) Digital Elevation Models and GIS for Watershed Modelling and Flood Prediction -A Case Study of Accra Ghana. In: Appropriate Technologies for Environmental Protection in the Developing World. Springer, pp 325-332

Lacroix M, Martz L, Kite G, Garbrecht J (2002) Using digital terrain analysis modeling techniques for the parameterization of a hydrologic model. Environ Model Softw 17(2):125-134

Lin WT, Chou WC, Lin CY, Huang PH, Tsai JS (2008) WinBasin: using improved algorithms and the GIS technique for automated watershed modelling analysis from digital elevation models. Int J Geogr Inf Sci 22(1/2):47-69

MacMillan R, Martin T, Earle T, McNabb D (2003) Automated analysis and classification of landforms using high-resolution digital elevation data: applications and issues. Can J Remote Sens 29(5):592-606

Magnuson J, Webster K, Assel R, Bowser C, Dillon P, Eaton J, Evans H, Fee E, Hall R, Mortsch L (1997) Potential effects of climate changes on aquatic systems: laurentian great lakes and precambrian shield region. Hydrol Process 11 (8):825-871

Merkel W, Kaushika R, Gorman E (2008) NRCS GeoHydro-A GIS interface for hydrologic modeling. Comput \& Geosciences 34(8):918-930

Moharana P, Kar A (2002) Watershed simulation in a sandy terrain of the Thar desert using GIS. J Arid Environ 51(4):489-500

Murphy P, Ogilvie J, Meng F, Arp P (2007) Stream network modelling using lidar and photogrammetric digital elevation models: a comparison and field verification. Hydrol Process 22(12):1747-1754

Saunders W (2000) Preparation of DEMs for use in environmental modeling analysis. Hydrologic and hydraulic modeling support with geographic information systems. ESRI Press, New York, pp 29-52

Turcotte R, Fortin J, Rousseau A, Massicotte S, Villeneuve J (2001) Determination of the drainage structure of a watershed using a digital elevation model and a digital river and lake network. J Hydrol 240(3-4):225-242

Wu S, Li J, Huang G (2008) A study on DEM-derived primary topographic attributes for hydrologic applications: sensitivity to elevation data resolution. Appl Geogr 28(3):210-223

Zhang H, Huang G (2009) Building channel networks for flat regions in digital elevation models. Hydrol Process 23(20):2879-2887

Zhang H, Huang GH, Wang D (2013) Establishment of channel networks in a digital elevation model of the prairie region through hydrological correction and geomorphological assessment. Can Water Resour J 38(1):12-23

doi:10.1186/2193-2697-3-11

Cite this article as: Li: Watershed modeling using arc hydro based on DEMs: a case study in Jackpine watershed. Environmental Systems Research 2014 3:11.

\section{Submit your manuscript to a SpringerOpen ${ }^{\circ}$ journal and benefit from:}

- Convenient online submission

- Rigorous peer review

- Immediate publication on acceptance

- Open access: articles freely available online

- High visibility within the field

- Retaining the copyright to your article

Submit your next manuscript at $>$ springeropen.com 